\title{
Increased perinatal intracranial pressure and prediction of early puberty in girls with myelomeningocele
}

\author{
L A Proos, M Dahl, G Ahlsten, T Tuvemo, J Gustafsson
}

\begin{abstract}
An increased risk of developing precocious puberty has been reported in children with myelomeningocele. In order to evaluate this further and to study factors associated with early or precocious puberty the medical records of all girls with myelomeningocele, born from 1970 onwards $(n=64)$, who were admitted to our unit were reviewed. Early/precocious puberty (E/PP) was defined as breast development or pubic hair corresponding to Tanner stage 2 before the age of 9.2 years. In 32 out of 64 cases data were sufficient for evaluation of the timing of puberty. Twenty girls had E/PP and 12 girls normal timing of puberty. In the girls who had reached the age of 9.2 years the incidence of E/PP was at least $52 \%$.

Girls with E/PP had a higher incidence of hydrocephalus, were treated with intraventricular shunts more often, and had significantly higher frequency of increased intracranial pressure during the perinatal period $(p<0.05, p<0.01$, and $p<0.001$, respectively). The group of girls developing E/PP was also more severely disabled with respect to motor and urological function and had more shunt revisions.
\end{abstract}

In conclusion, E/PP in girls with myelomeningocele is strongly associated with increased intracranial pressure particularly during the perinatal period.

(Arch Dis Child 1996;75:42-45)

Keywords: precocious puberty, myelomeningocele, intracranial pressure.

Precocious or early pubertal development in patients with myelomeningocele has been reported in several studies. ${ }^{1-5}$ The incidence of precocious puberty in these studies has varied between 5 and $35 \%$. The occurrence of advanced bone age has also been reported. ${ }^{6} \mathrm{~A}$ majority of the patients with myelomeningocele and early puberty have also been found to have hydrocephalus. As reported studies have been based on heterogeneous groups of patients or selected materials, it is difficult to draw any conclusions regarding incidence or possible risk factors for early or precocious puberty in children with myelomeningocele.
Precocious puberty occurs in general more frequently in girls than in boys. ${ }^{7}$ In our clinical experience girls with myelomeningocele are particularly prone to develop early or precocious puberty (E/PP). In these patients early appearance of secondary sexual characteristics and early onset of menstruation may lead to practical and psychological problems in addition to those already caused by the myelomeningocele. ${ }^{8}$ Identification of predictors for development of precocious puberty is thus important for prevention and treatment of the condition.

The aims of the present study were to investigate the incidence of E/PP in girls with myelomeningocele treated at a regional habilitation centre, the Folke Bernadotte Home, and to identify possible risk factors associated with the occurrence of early or precocious puberty.

\section{Patients and methods}

STUDY POPULATION

The Folke Bernadotte Home is a division of the Department of Paediatrics at the Uppsala University Children's Hospital and is the paediatric habilitation centre for a region with a population of 1.2 million inhabitants. Most of the children with myelomeningocele in the region are regularly admitted to the Folke Bernadotte Home for medical assessment and/or intensive training. The majority of these patients have previously been treated at the Department of Paediatric Surgery. The study population comprised all girls born between 1970 and 1992 admitted to the Folke Bernadotte Home at least once. Sixty four girls fulfilled these criteria. Of these, 59 came from our region and five from other regions. Ten of the 64 girls were below 3 years of age at the latest admission, whereas 25 girls were between 3 and 9.1 years and 29 girls above 9.2 years (table 1). In 31 out of the 64 cases either the data recorded were insufficient for evaluation of $\mathrm{E} / \mathrm{PP}$, or the child was very young. One girl had Turner's syndrome and was excluded from further analysis. In the remaining patients $(n=32,50 \%)$ evaluation of the timing of puberty was possible, and these patients constituted the final study population (table 1).

\section{STUDY METHODS}

The hospital records of the patients from the Folke Bernadotte Home and the Department of Paediatric Surgery were evaluated. Pubertal 
Table 1 Study population

\begin{tabular}{llllll}
\hline $\begin{array}{l}\text { Age at latest } \\
\text { admission } \\
\text { (years) }\end{array}$ & No of patients & $\begin{array}{l}\text { Patients with } \\
\text { sufficient data } \\
\text { for pubertal } \\
\text { evaluation }\end{array}$ & E/PP & $\begin{array}{l}\text { \% E/PP in } \\
\text { patients with } \\
\text { sufficient data }\end{array}$ & $\begin{array}{l}\text { \% E/PP in all } \\
\text { patients }\end{array}$ \\
\hline$<3$ & 10 & 0 & - & - & - \\
$3-9.1$ & 25 & 5 & 5 & 100 & 20 \\
$\geqslant 9.2$ & 29 & 27 & 15 & 56 & 52 \\
Total & 64 & 32 & 20 & 63 & 31 \\
\hline
\end{tabular}

Table 2 Factors associated with E/PP in 32 children with myelomeningocele

\begin{tabular}{|c|c|c|c|}
\hline & $\begin{array}{l}E / P P \\
(n=20)\end{array}$ & $\begin{array}{l}\text { Normal puberty } \\
(n=12)\end{array}$ & p Value \\
\hline $\begin{array}{l}\text { 1. Perinatal increase of intracranial } \\
\text { pressure }\end{array}$ & $17 / 18^{\star}$ & 1 & $<0.001$ \\
\hline 2. Intraventricular shunt & 20 & 7 & $<0.01$ \\
\hline 3. Hydrocephalus & 20 & 8 & $<0.05$ \\
\hline 4. Shunt revisions (two or more) & 12 & 2 & $<0.05$ \\
\hline 5. Non-ambulant (wheelchair) & 14 & 4 & $<0.05$ \\
\hline 6. Urological complications ${ }^{\dagger}$ & 6 & 0 & $<0.05$ \\
\hline
\end{tabular}

* Classification of intracranial pressure perinatally was possible only in 18 patients in the E/PP group.

† Urological operation, that is vesicostomy, bladder augmentation, or reimplantation.

status, perinatal problems, other medical and functional problems as well as the nature and effects of the neurological lesion were analysed with the aid of a prestructured schedule. Moreover, the presence of perinatal clinical signs of increased intracranial pressure was investigated. The incidence of hydrocephalus and shunt treatment was noted. The patients were classified with regard to the timing of their pubertal development.

E/PP was defined as breast development and/or pubic hair corresponding to Tanner stage 2 before the age of 9 years and 2 months (9.2 years) which is below $-2 \mathrm{SD}$, according to Swedish standards. ${ }^{9}$ Although the definition is based on the timing of breast development, the somewhat later sign of pubic hair is included as in a few cases it was the earliest pubertal sign noted in the hospital record.

The patients were also grouped according to absence or presence of signs of increased intracranial pressure at birth and during the first week after birth, that is, the perinatal period. Sufficient data for such classification

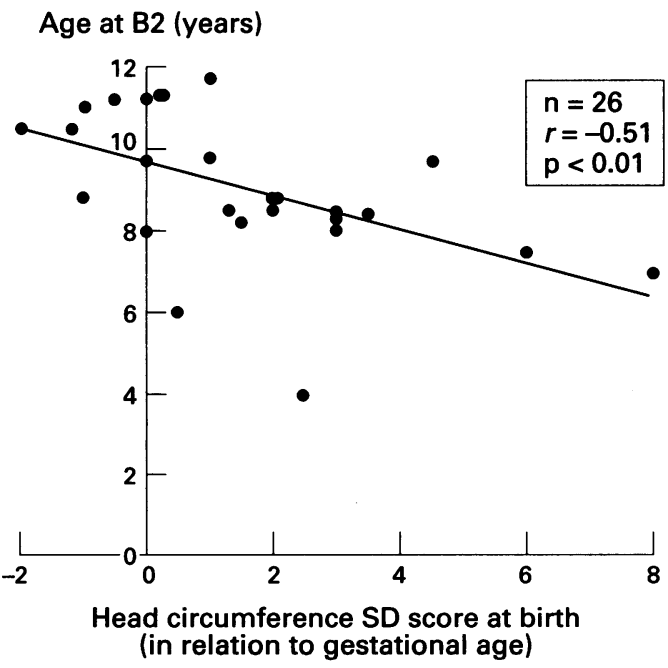

Figure 1 Age at breast development Tanner stage 2 (B2) in relation to head circumference $S D$ score at birth (related to gestational age). were found in the hospital records of 30 of the 32 girls included in the final study population.

Increased intracranial pressure perinatally was considered present if there were wide sutures, bulging fontanelle, and rapidly increasing head circumference during the first week after birth.

Head circumference and weight at birth were in all instances related to gestational age. ${ }^{10}$

\section{STATISTICAL ANALYSIS}

Statistical differences between the groups with and without precocious puberty (table 2) were calculated by means of Fisher's exact test. The relationship between perinatal head circumference data and timing of pubertal maturation was analysed by calculation of linear regression and Pearson's correlation coefficient. ${ }^{11}$

\section{Results}

CLINICAL CHARACTERISTICS

The median length of gestation was 40 weeks (range 36-42 weeks). The median birth weight was $3450 \mathrm{~g}(2410-4661 \mathrm{~g})$. Ten girls were delivered by caesarean section. Two girls were asphyxiated postpartum, while the other 30 girls were in good condition after birth.

The functional neurological level was high lumbar or thoracic (L3 or above) in 17 children, low lumbar (L4, L5) in eight, and sacral in six. One child had no motor paralysis. All except two children showed signs and symptoms of impaired urinary bladder function.

Twenty eight children had hydrocephalus and 27 of these had a shunt inserted (see table 2). Eleven out of 32 patients had an additional neurological handicap (mental retardation, epilepsy or both).

\section{OCCURRENCE OF E/PP}

Of the 32 girls possible to evaluate, 20 were found to have E/PP. Five of these were under 8 years of age and the youngest under 5 at the start of puberty. Of the 29 girls who had reached at least 9.2 years at latest admission, 27 had sufficient data for evaluation. Fifteen of these had E/PP. Among the girls 3-9.1 years old at latest admission five had E/PP, but in this age group adequate data were lacking for 20 girls (table 1).

The mean (SD) age at attainment of breast development Tanner stage 2 (stage B2) in the group with E/PP was $7.9(1.3)$ years (range 4.0-8.8 years) compared with $10.7(0.7)$ years (range 9.7-11.7 years) in the group with normal puberty.

PREDICTORS OF E/PP

In a univariate analysis, the 20 girls with $\mathrm{E} / \mathrm{PP}$ were compared with the 12 children with normal timing of puberty, with regard to possible risk factors associated with the occurrence of $\mathrm{E} / \mathrm{PP}$ (table 2).

The girls with E/PP had a significantly higher frequency of hydrocephalus, increased intracranial pressure during the perinatal period, and intraventricular shunt treatment than the group of girls with normal puberty. In addition the girls with E/PP had more prob- 
lems with motor disability and more urological complications. No significant differences were found between the two groups with respect to instrumental delivery, gestational age, birth weight, or presence of additional neurological disability (table 2).

As shown, the strongest predictor was the increase in perinatal intracranial pressure in girls with E/PP. A negative relationship ( $p<0.01, r=-0.51)$ between head circumference at birth and age at attaining stage B2 was found (fig 1). Further analysis showed that 10 out of the 18 girls with clinical signs of increased intracranial perinatal pressure also had a head circumference $\geqslant 2$ SD scores above their SD score for weight at birth. Nine of these 10 girls were in the E/PP group.

\section{Discussion}

The present study shows the occurrence of a markedly increased incidence of $\mathrm{E} / \mathrm{PP}$ in girls with myelomeningocele. The incidence figure for $\mathrm{E} / \mathrm{PP}$ in our group evaluated at $\geqslant 9.2$ years of age was at least $52 \%$. This figure is higher than those reported earlier. ${ }^{2356}$ In the age group evaluated at 3-9.1 years of age, all five girls with sufficient data were found to have E/PP. The lack of pubertal data in the records of the remaining 20 patients in this age group could be due either to the absence of pubertal signs or incomplete examination. As in the older age group the incidence found, $20 \%$, thus represents a minimal figure.

The variation in incidence between our study and those reported earlier ${ }^{2356}$ may be due to differences in population characteristics. Lack of awareness that patients with myelomeningocele are at risk for early puberty may have caused under-reporting. Our subjects comprised patients referred to a regional (tertiary) unit and may therefore consist of more severe cases, that is, more prone to develop E/PP. On the other hand, the patients with the most severe conditions do not survive up to an age when E/PP might have become manifest, as the mortality figures for myelomeningocele are high. ${ }^{5} \mathrm{~A}$ review of girls with myelomeningocele treated at the Department of Paediatric Surgery at Uppsala University Children's Hospital showed that $13 \%$ died at an early age.

Another possible cause of variation in incidence may be different and arbitrary definitions of E/PP. ${ }^{12}$ We have chosen the age corresponding to $-2 \mathrm{SD}$ for attainment of breast development Tanner stage B2 for Swedish girls when defining early pubertal development. 9 As can be seen from the widely separated mean ages for attainment of stage B2 in the groups with and without $\mathrm{E} / \mathrm{PP}$, this definition separates what appears to be two different populations. Five of the E/PP girls fit the often used definition of precocious puberty (that is puberty in girls less than 8 years of age) and they thus represent the earliest in our population of early maturers.

In the present study a clear association between E/PP and increased intracranial pressure in the perinatal period was found. Several earlier studies have pointed out an association between hydrocephalus and early pubertal development. ${ }^{13-17}$ Increased intracranial pressure with dilatation of the third ventricle and possible damage to the hypothalamic-pituitary axis has been postulated as a causative mechanism. ${ }^{13}$ The same mechanism has been suggested to occur in children suffering from myelomeningocele with hydrocephalus. ${ }^{2}$ Other factors may also be operative as a lack of relationship between the increase in head circumference and pubertal stage/bone age was noted in one study. ${ }^{3}$

To the best of our knowledge, this study is the first to show a clear relationship between a perinatal increase in intracranial pressure and development of E/PP. An increase in intracranial pressure occurring perinatally may indicate a prenatal lesion. The importance of the timing of the lesion appears evident from the fact that hydrocephalus alone is not necessarily associated with development of E/PP. Increased intracranial pressure manifested by the development of hydrocephalus was associated with E/PP in this study only if there were signs of increased intracranial pressure early in life, that is, perinatally. The association between increased head circumference at birth and $\mathrm{E} / \mathrm{PP}$ indicates a possible intracranial causative factor, and might be clinically useful as a prognostic sign.

The higher incidence of shunt revisions, non-ambulatory conditions, and urological complications in the patients with $\mathrm{E} / \mathrm{PP}$ may indicate a more severe primary malformation complex than in the patients with normal puberty.

Although the precise aetiology of E/PP remains unknown as yet, it is clearly established that patients with myelomeningocele are at extremely high risk for early pubertal development.

Consequently, the development of patients with myelomeningocele should be closely monitored with regular recording of pubertal stages and measurement of growth rate and weight. This is particularly important for patients with an early increase in intracranial pressure. It should be remembered that height measurements may be misleading in this particular group of patients. Arm span may be a more reliable parameter when monitoring linear growth. ${ }^{18}$ As an efficient and safe treatment with gonadotrophin releasing hormone analogues, blocking pubertal development, is available, ${ }^{19}$ early detection of $\mathrm{E} / \mathrm{PP}$ in patients with myelomeningocele is important.

We thank Professor Gunnar Eklund for statistical advice.

1 Dalton ME, Dalton K. Menarcheal age in the disabled. BMF 1978; ii: 475.

2 Meyer S, Landau $\mathrm{H}$. Precocious puberty in myelomeningocele patients. $\mathcal{F}$ Pediatr Orthop 1984; 4: 28-31.

3 Greene SA, Frank M, Zachmann M, Prader M. Growth and sexual development in children with meningomyelocele. Eur $\mathcal{F}$ Pediatr 1985; 144: 146-8.

4 Hunt GM. Spina bifida: implications for 100 children at school. Dev Med Child Neurol 1981; 23: 160-72.

5 Hunt GM. Open spina bifida outcome for a complete cohort treated unselectively and followed into adulthood. cohort treated unselectively and followed
Dev Med Child Neurol 1990; 32: 108-18.

6 Kalen V, Harding CR. Skeletal maturity in myelodysplasia. Dev Med Child Neurol 1994; 36: 528-32.

7 Bertrand J, Rappaport R, Sizonenko P, eds. Pediatric endocrinology, physiology, pathophysiology and clinical aspects.
2nd Ed. Baltimore: William and Wilkins, 1993. 
8 Dahl M, Ahlsten G, Carlson H, et al. Neurological dysfunction above cele level in children with spina bifida cystica. A prospective study to three years. Dev Med Child Neurol 1995; 37:30-40.

9 Karlberg $P$, Taranger J. The somatic development of children in a Swedish urban community. A prospective children in a Swedish urban community. A prospective

10 Niklasson A, Ericsson E, Fryer JG, Karlberg J, Lawrence C, Karlberg P. An update of the Swedish reference standards for weight, length and head circumference at birth for given gestational age (1977-1981). Acta Paediatr Scand 1991; 80: 756-62.

11 SAS Institute Inc. SAS/STAT guide for personal computers. Version 6.03 edition. Cary, NC: SAS Institute Inc, 1988.

12 Behrman RE, Vaughan VC, Nelson WE, eds. Nelson textbook of pediatrics. Philadelphia: WB Saunders, 1987:1186.

13 Fernell E, Hagberg B, Hagberg G. Epidemiology of infantile hydrocephalus in Sweden: a clinical follow-up study in children born at term. Neuropediatrics 1988; 19: 135-42.
14 Hagberg B, Sjögren I. The chronic brain syndrome of infantile hydrocephalus. $A m \mathcal{F}$ Dis Child 1966; 112: 189-95.

15 Kaiser G, Ruedeberg A, Arnold M. Endocrinological disorders in shunted hydrocephalus. $Z$ Kinderchir 1989; 44(suppl 1): 16-7.

16 Brauner $R$, Rappaport $R$, Nicon $C$, et al. Pubertés précoces vraies au cours de l'hydrocephalie non tumorale. Arch Fr vediatr 1987; 44: 433-6.

17 De Luca F, Muritano M, Rizzo G, Pandullo E, Cardia E. True precocious puberty: a long-term complication in children with shunted non-tumoral hydrocephalus. Helv Paediatr Acta 1985; 40: 467-72.

18 Rosenblum MF, Finegold DN, Charney EB. Assessment of stature of children with myelomeningocele, and usefulness of arm-span measurement. Dev Med Child Neurol 1983; 25: 238-42.

19 Crowley Jr WF, Comite F, Vale W, et al. Therapeutic use of pituitary desensitization with a long-acting LHRH agonist: a potential new treatment for idiopathic precocious puberty. F Clin Endocrinol Metab 1981; 52: 370-2. 